\title{
Loss of Ras activity in Saccharomyces cerevisiae is suppressed by disruptions of a new kinase gene, YAKI, whose product may act downstream of the cAMP- dependent protein kinase
}

\author{
Stephen Garrett and James Broach ${ }^{1}$ \\ Department of Biology, Princeton university, Princeton, New Jersey 08544 USA
}

\begin{abstract}
The yeast Saccharomyces cerevisiae contains two functionally redundant genes RAS1 and RAS2, which are homologous to the mammalian ras gene family and are required for vegetative growth. We isolated and characterized five temperature-sensitive alleles of RAS2. In a ras1 strain, these alleles cause growth arrest at the $G_{1}$ stage of the cell cycle. Revertants capable of growth at the nonpermissive temperature define four recessive, extragenic complementation groups. Suppressors in one complementation group (designated yak1) are particularly intriguing because they appear to alleviate only the growth defect of the temperature-sensitive ras mutants and do not show any of the phenotypes, such as heat shock sensitivity or starvation sensitivity, associated with increased production of cAMP. The YAK1 gene has been cloned, and disruptions generated in vitro reveal that it is not essential for growth and that its loss confers growth to a strain deleted for tpk1, tpk2, and tpk3, the structural genes for the catalytic subunit of the cAMP-dependent protein kinase. These results place Yak1 downstream from, or on a parallel pathway to, the kinase step in the Ras/cAMP pathway. Finally, the coding region predicts a protein with significant homology to the family of protein kinases, suggesting that loss of cAMP-dependent protein kinase function can be suppressed by the loss of a second protein kinase.
\end{abstract}

[Key Words: YAK1; kinase; S. cerevisiae; cAMP; RAS]

Received June 2, 1989; revised version accepted July 19, 1989.

In the yeast Saccharomyces cerevisiae, cAMP and its attendant proteins play a crucial role in cell-cycle progression. A cell deficient in the synthesis of cAMP arrests growth as an unbudded cell early in $\mathrm{G}_{1}$, at a stage commonly known as 'START' (Pringle and Hartwell 1981). Some of the genes necessary for cAMP synthesis and turnover have been identified and their roles in the cAMP pathway are shown in Figure 1. These include CYR1 (Matsumoto et al. 1982; Boutelet et al. 1985; Casperson et al. 1985; Kataoka et al. 1985), the structural gene for adenylate cyclase, as well as two homologs of the mammalian ras oncogenes, RAS1 and RAS2 (DefeoJones et al. 1983; Kataoka et al. 1984; Powers et al. 1984). The products of the latter two genes are membrane-associated GTP-binding proteins (Fujiyama and Tamanoi 1986; Powers et al. 1986; Deschenes and Broach 1987) that stimulate adenylate cyclase (Toda et al. 1985). A fourth protein necessary for cAMP production is the product of the cell-division cycle gene CDC25 (Camonis et al. 1986; Broek et al. 1987; Robinson et al. 1987). Although the role of Cdc25 is not understood, genetic evidence suggests that it may function to activate

'Corresponding author. the Ras proteins, which, in turn, stimulate adenylate cyclase (Camonis et al. 1986; Broek et al. 1987). Two other genes, PDE1 and PDE2, encode the low- and high-affinity cAMP phosphodiesterases, respectively (Sass et al. 1986; Nikawa et al. 1987b).

The primary function of cAMP in most eukaryotes, including yeast, is activation of the cAMP-dependent protein kinase (cAPK). This activation occurs by cAMP binding to the kinase regulatory subunit and causing its dissociation from the catalytic subunit. Genetic and sequence analysis has shown that the catalytic subunits are encoded by three functionally redundant genes, TPK1, TPK2, and TPK3 (Cannon and Tatchell 1987; Toda et al. 1987b|, whereas a single gene, $B C Y 1$, specifies the regulatory subunit (Uno et al. 1982; Cannon and Tatchell 1987; Kunisawa et al. 1987; Toda et al. 1987a). Toda et al. (1987b) have shown that the cell-cycle defect of a CAMP-deficient strain can be suppressed by overexpression of one of the TPK genes or by disruption of $B C Y 1$. Thus, to a first approximation, the role of cAMP in cell-cycle progression can be explained entirely by the cAMP-dependent phosphorylation of one or more cellular substrates. Although components of the Ras/cAMP pathway required for activation of the cAPK are well es- 
tablished, almost nothing is known about the proteins whose cAMP-dependent phosphorylation is essential for cell-cycle progression. Several enzymes involved in carbon storage and metabolism have been shown to be regulated by their phosphorylation state (e.g., PFK2, NAD-dependent glutamate dehydrogenase, trehalase; Uno et al. 1983b, 1984a). However, no straightforward link exists between the function of these genes and progression through the cell cycle.

Several groups have isolated unlinked suppressors of ras and cyr 1 mutations as a means of identifying other components in the Ras/cAMP pathway. Tatchell and colleagues (Cannon et al. 1986) exploited the inability of a $R A S 1$ ras 2 strain to grow on nonfermentable carbon sources (Tatchell et al. 1985). By selecting revertants able to grow on ethanol $(\mathrm{EtOH})$ and acetate, they identified several genes, including BCY1 and PDE2 (Cannon and Tatchell 1987; Wilson and Tatchell 1988), whose products have been shown to function in the Ras/cAMP pathway. A different approach was taken by Fasano and colleagues (De Vendittis et al. 1986), who isolated revertants of a strain that was conditional for growth as a result of a temperature-sensitive ras2 allele. One of the suppressors was shown to have lost a potential phosphorylation site of adenylate cyclase. An explanation for the biochemical basis for this suppression is that the mutation activates adenylate cyclase by diminishing feedback inhibition from the cAMP-dependent protein kinase (De Vendittis et al. 1986; Nikawa et al. 1987b; Resnick and Racker 1988). Finally, the ira1 (formerly ppd1) mutation was isolated as a suppressor of an undefined defect in the Ras/cAMP pathway and most likely defines the gene for an inhibitor of Ras as shown in Figure 1 (Uno et al. 1984b; Matsumoto et al. 1985; Tanaka et al. 1989).

Despite the previous isolation of second-site suppressors of mutations in the Ras/cAMP pathway, we decided to undertake a similar mutant hunt by isolating temperature-sensitive ras 2 mutants and using them to isolate revertants. Our reasons for undertaking this project were as follows. First, the scheme used by Cannon and Tatchell relies on the ability of the RAS1 ras2 revertants to grow on nonfermentable carbon sources. Although this selection identified several new genes in the Ras pathway, we reasoned that this regimen biased the types of revertants that might be obtained, particularly in light of the evidence pointing to the inter-relationship between cAMP-dependent phosphorylation and carbon metabolism (Fraenkel 1985; Breviario et al. 1986; Tatchell et al. 1986; Fasano et al. 1988; Cherry et al. 1989|. Second, whereas Fasano and colleagues (De Vendittis et al. 1986) used a selection identical to ours, they concentrated on only one suppressor, and it was in a known gene, CYR1. Finally, some genes for proteins known to be involved in the Ras/cAMP pathway, for example, those encoding protein phosphatases (Wingender-Drissen and Becker 1983), have not been identified yet.

The following communication describes the isolation and characterization of five independent, temperature- sensitive mutations in the RAS2 gene, as well as the isolation of revertants of the resulting conditional-growth defect. Characterization of the revertants has shown that the suppressors fall into four major recessive complementation groups. One of the suppressors has been cloned, and its sequence reveals a large open reading frame that predicts a protein bearing significant homology to protein kinases. Disruptions of the gene are not lethal and support growth of a strain lacking the three genes for the catalytic subunits of cAPK.

\section{Results}

Isolation of ras $2^{\text {ts }}$ mutations

To isolate a collection of temperature-sensitive mutations in RAS2, we took advantage of the gene replacement technique described previously (Winston et al. 1983). A RAS2 fragment marked with the selectable $U R A 3$ gene was mutagenized in vitro and used to transform a ras $1::$ HIS3 RAS2 strain to $\mathrm{Ura}^{+}$at $25^{\circ} \mathrm{C}$. Approximately $30,000 \mathrm{Ura}^{+}$colonies were tested on both minimal medium and rich (YEPD) medium for a growth defect at the nonpermissive temperature $35^{\circ} \mathrm{C}$. Five colonies $(0.017 \%)$ exhibited temperature-sensitive growth on rich medium and were candidates for ras $2^{\text {ts }}$ mutants.

The five temperature-sensitive strains were shown to contain mutations in Ras 2 by several criteria, including complementation tests with a low-copy CEN RAS2 plasmid (pGS21) and diploid analysis. The inability of diploids formed with a ras $2:: L E U 2$ strain to grow on $\mathrm{EtOH}$ was taken as evidence that conditional growth was the result of a mutation in RAS2. In addition, the temperature-sensitive phenotype cosegregated with the URA3 marker in all five mutants. Finally, the mutations were shown to reside within the 1.1-kb Hpal RAS2 fragment (Powers et al. 1984) by marker rescue with a gapped version of a RAS2 CEN vector (pGS22), and subsequent transplacement of a ras1 :: HIS3 RAS2 strain to $\mathrm{Ura}^{+}$and temperature-sensitive growth with the recovered DNA (data not shown).

Because yeast Ras is essential for adenylate cyclase activity, two of the ras $2^{\text {ts }}$ mutants were tested for phenotypes, other than loss of growth, related to the loss of cAMP. Such phenotypes include increased glycogen accumulation and $\mathrm{G}_{1}$-specific cell-cycle arrest (De Vendittis et al. 1986). As expected, the temperature-sensitive mutants were shown to behave in a manner consistent with their containing conditional ras 2 mutations (data not shown). In addition, the growth defect of the temperature-sensitive strains was shown to be related to their inability to accumulate cAMP by transplacing the ras $1::$ HIS3 and ras $2^{\text {ts }}-$ URA3 mutations into a cAMPpermeable strain (Matsumoto et al. 1982) derived from strain 460 (Table 1) and observing growth at $35^{\circ} \mathrm{C}$ on medium containing exogenous cAMP (Fig. 2).

\section{Revertant isolation}

To increase the spectrum of mutations isolated as suppressors of the Ras ${ }^{-}$defect, we selected revertants of 


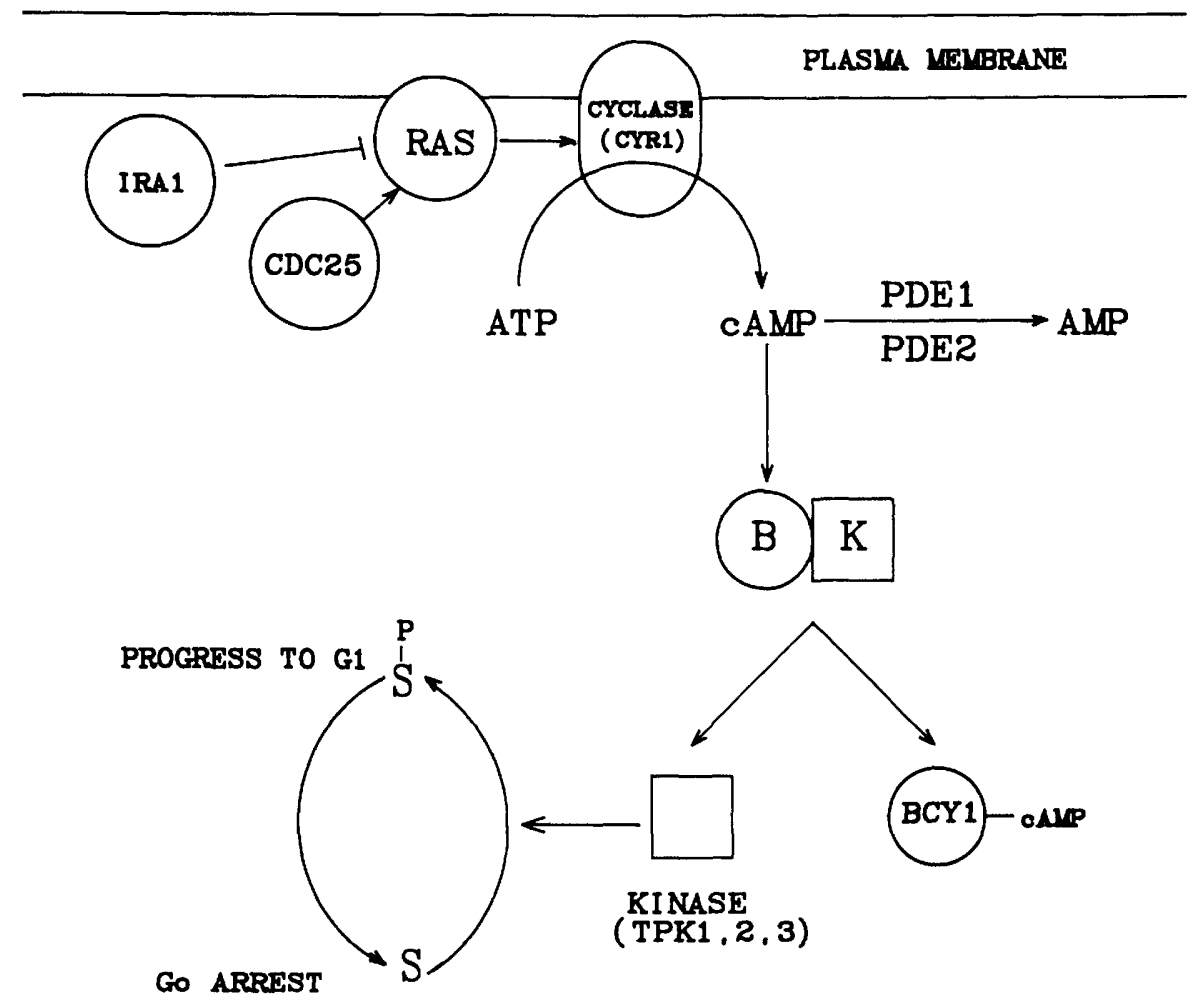

Figure 1. Model of the Ras pathway in yeast.

isogenic MATa strains containing either of two independent temperature-sensitive mutations, ras2-11 (SGP11) and ras2-34 (SGP34). Thirty revertants of a MATa strain (SGP10) carrying the ras2-34 allele also were selected to facilitate complementation analysis. Single colonies grown at the permissive temperature were patched to glucose-rich medium and grown for several days at $35^{\circ} \mathrm{C}$. The number of colonies that grew from a patch varied but rarely exceeded six. To ensure that all of the suppressors were independent only one colony from each patch was purified and retested for growth at the nonpermissive temperature. Over 120 revertants from each of the MAT $\alpha$ temperature-sensitive mutants were isolated and subjected to genetic analysis.

Complementation tests were performed to assign the recessive suppressors to individual loci. Revertants of the $\alpha$ strain were mated to a strain revertants, as described in Materials and methods, and the diploids were tested for growth at the nonpermissive temperature, with either glucose, galactose or EtOH/glycerol as the carbon source. The results of the diploid analysis are summarized in Table 2. Approximately $10 \%$ of the revertants contained dominant mutations, in agreement with previous results (Cannon et al. 1986).

The remainder of the revertants fell into five major classes: four distinct complementation groups which, in sum, constituted $55 \%$ of the temperature-resistant strains and a class, comprised of $35 \%$ of the strains, that remain unassigned. Strains in this class were not assigned to complementation groups either because their growth properties on diploid analysis were unclear or they were the lone representative of that group.

Recessive suppressors define at least four complementation groups

Because several recessive suppressors of the Ras pathway have been described previously in $S$. cerevisiae, we performed genetic tests to determine whether our suppressors defined any of the same genes. The gene $B C Y 1$ encodes the regulatory subunit of the CAPK. Disruption of $B C Y 1$ has been shown to alleviate the growth defect of a ras1 ras2 strain (Matsumoto et al. 1982; Cannon and Tatchell 1987; Toda et al. 1987a). A bcy1 :: LEU2 disruption was shown to suppress the growth defect of the ras 1 ras $2^{\text {ts }}$ strains, and subsequent diploid analysis showed that suppressors of one major complementation group were allelic with $b c y 1$ (Table 2). This was confirmed by complementation tests with a high-copy plasmid vector (YEp 13) containing BCY1.

Mutations in the genes PDE1 and PDE2 eliminate the high- and low $-K_{\mathrm{m}}$ cAMP phosphodiesterase, respectively (Uno et al. 1983a; Sass et al. 1986; Nikawa et al. 1987b; Wilson and Tatchell 1988). Disruptions of PDE2 allow growth of a RAS1 ras2 strain on EtOH, presumably by decreasing the cAMP turnover of the cell (Sass et al. 1986; Wilson and Tatchell 1988). To investigate whether one of the three remaining complementation groups defined either phosphodiesterase gene, disruptions of PDE1 (pde1::LEU2) or PDE2 (pde2:: URA3) were 
Table 1. Strain and plasmid list

\begin{tabular}{|c|c|c|}
\hline Strain/plasmid & Genotype & Source \\
\hline \multicolumn{3}{|l|}{ Strains } \\
\hline SGP3 & MAT $\alpha$ leu2-3,112 trp1 ura3-52 his3 ras1 :: HIS3 RAS2 & this study \\
\hline SGP4 & SGP3 RAS2-URA3 & from SGP3 \\
\hline SGP11 & SGP3 ras 2 ts $11-U R A 3$ & from SGP3 \\
\hline SGP19 & SGP3 ras2ts19-URA3 & from SGP3 \\
\hline SGP23 & SGP3 ras $2 t s 23-U R A 3$ & from SGP3 \\
\hline SGP31 & SGP3 ras $2 t s 31-U R A 3$ & from SGP3 \\
\hline SGP34 & SGP3 ras2ts34-URA3 & from SGP3 \\
\hline SGP10 & MATa leu2-3,112 trp1 ura3-52 his3 ras1 :: HIS3 ras2ts34-URA3 & this study \\
\hline 703 & MAT $\alpha$ leu2-3,112 trp1 ura3-52 ade1 ade2 cdc25-1 & laboratory stock \\
\hline T50-3A & MAT $\alpha$ leu2-3,112 trp1 ura3-52 his3 cyr1-2 cam & Kataoka et al. (1985) \\
\hline$S 7-7 \mathrm{~A} \times \mathrm{S} 7-5 \mathrm{~A}$ & $\begin{array}{l}\text { MATa/MATa TPK1/tpk1 :: URA3 TPK2/tpk2 :: HIS3 } \\
\text { TPK3/tpk3 :: TRP1 ura3/ura3 his3/his3 trp1/trp1 leu2/leu2 } \\
\text { ade8/ade8 }\end{array}$ & Toda et al. $(1987 \mathrm{~b})$ \\
\hline SGP9 & $\begin{array}{l}\text { MATa/MATa RAS1/ras1 :: HIS3 RAS2/ras2 :: URA3 his3/his3 } \\
\quad \text { ura3-52/ura3-52 leu2-3,112/leu2-3,112 }\end{array}$ & this study \\
\hline 1029 & $\begin{array}{l}\text { MATa/MAT } \alpha \text { his3/his3 ura3-52/ura3-52 leu2-3,112/leu2-3,112 } \\
\text { lys2/lys2 ADE2/ade2 TRP1/trp1 }\end{array}$ & laboratory stock \\
\hline SGP40 & MATa ras1 :: HIS3 RAS2 leu2-3,112 ura3-52 his3 ade & this study \\
\hline SGP400 & MATa leu2-3,112 trp1 ura3-52 his3 RAS2 yak1 :: LEU2 & from SGP9 \\
\hline SGP430 & MATa leu2-3,112 trp1 ura3-52 his3 ras2 :: URA3 YAK1 & from SGP9 \\
\hline SGP431 & MATa leu2-3,112 trp1 ura3-52 his3 ras2 :: URA3 yak1 :: LEU2 & from SGP9 \\
\hline SGP406 & $\begin{array}{l}\text { MATa leu2-3,112 trp1 ura3-52 his3 tpk1 :: URA3 } \\
\quad \text { tpk2 }:: \text { HIS3 tpk3 }:: \text { TRP1 yak1 }:: \text { LEU2 }\end{array}$ & $\begin{array}{l}\text { from } \mathrm{S} 7-7 \mathrm{~A} \times \mathrm{S} 7-5 \mathrm{~A} \\
\text { transformed with yak1 ::LEU2 }\end{array}$ \\
\hline SGP432 & $\begin{array}{l}\text { MAT } 1 \text { leu2-3,112 trp1 ura3-52 his3 tpk1 :: URA3 tpk2 :: HIS3 } \\
\quad \text { tpk3 :: TRP1 yak1 :: LEU2 }\end{array}$ & as SGP406 \\
\hline \multicolumn{3}{|l|}{ Plasmids } \\
\hline pSB32 & CEN4 ARS4 LEU2 & J. Truehart, unpubl. \\
\hline pGS65 & CEN4 ARS4 LEU2 (SalI+) & this study \\
\hline YCP50 & CEN4 ARS4 URA3 & Rose and Fink 1987 \\
\hline pGS21 & RAS2 in pSB32 & this study \\
\hline pGS22 & $\Delta$ ras $2-1$ in $\mathrm{pSB} 32$ & this study \\
\hline pGS100/101/102 & $Y A K 1$ in $\mathrm{pSB} 32$ & this study \\
\hline pRJ520-1 & RAS2-URA3 & Deschenes and Broach (1987) \\
\hline ppdel :: LEU2 & pde1 :: LEU2 & Nikawa et al. (1987b) \\
\hline ppde2 :: URA3 & pde2 :: URA3 & Sass et al. (1986) \\
\hline $\mathrm{p} b c y 1::$ LEU2 & bcy $1::$ LEU2 & Toda et al. (1987a) \\
\hline YEp13-BCY1 & $B C Y 1$ & Toda et al. (1987a) \\
\hline pGS129 & YAK1 in $\mathrm{CVO} 3$ & this study \\
\hline pGS130-2 & yak1 :: HIS3 & this study \\
\hline pGS136-A & yak1 :: LEU2 & this study \\
\hline
\end{tabular}

transplaced into the ras1 ras $^{\text {ts }}$ strains SGP34 or SGP42, respectively. The pde2 mutation, but not the pde1 mutation, appeared to suppress the growth defect of these strains. Thus, none of the complementation groups is likely to be allelic to PDE1. Complementation tests between the pde2 transformant and the revertants gave equivocal results for two of the complementation groups (referred to as sra9 and sra10, for Suppressor of RAs, Cannon et al. 1986). However, the pde2 mutant clearly complemented the yak1 revertants shown in Table 2; accordingly, YAK1 is a distinct gene from PDE2.

A single recessive mutation, ira1/ppd1, was isolated previously as a suppressor of a defect (cyr2) in the cAMP pathway (Matsumoto et al. 1985). Mutations in IRA1 also might be expected to suppress the ras $2^{\text {ts }}$ defect of the strains used in this selection, although they do not alleviate the growth defect of a strain carrying a dominant RAS2(Ts) mutation (Tanaka et al. 1989). Because
IRA1 has been mapped to the right arm of chromosome II, $7.7 \mathrm{cM}$ from LYS2, several suppressors from the complementation groups yak1, sra9, and sra10 were mapped relative to the lys2 allele of MATa ras1 :: HIS3 ras $^{\text {ts }}$ URA3 strain SGP10. None of the suppressor alleles tested exhibited linkage to LYS2 (results not shown). Therefore, ira1/ppd1 is not allelic with yak1, sra9, or sra10.

The pattern of suppression exhibited by the revertants of any one complementation group often can be used in subsequent characterization of the suppressors. Thus, the recessive revertants were tested for glycogen accumulation, growth on various carbon sources, heat shock sensitivity, and survival of nitrogen starvation, according to the procedures outlined in Materials and methods. The ras 2 bcy 1 revertants exhibited the widest phenotypic variation and included strains that appeared to accumulate less glycogen and were more sensitive to 


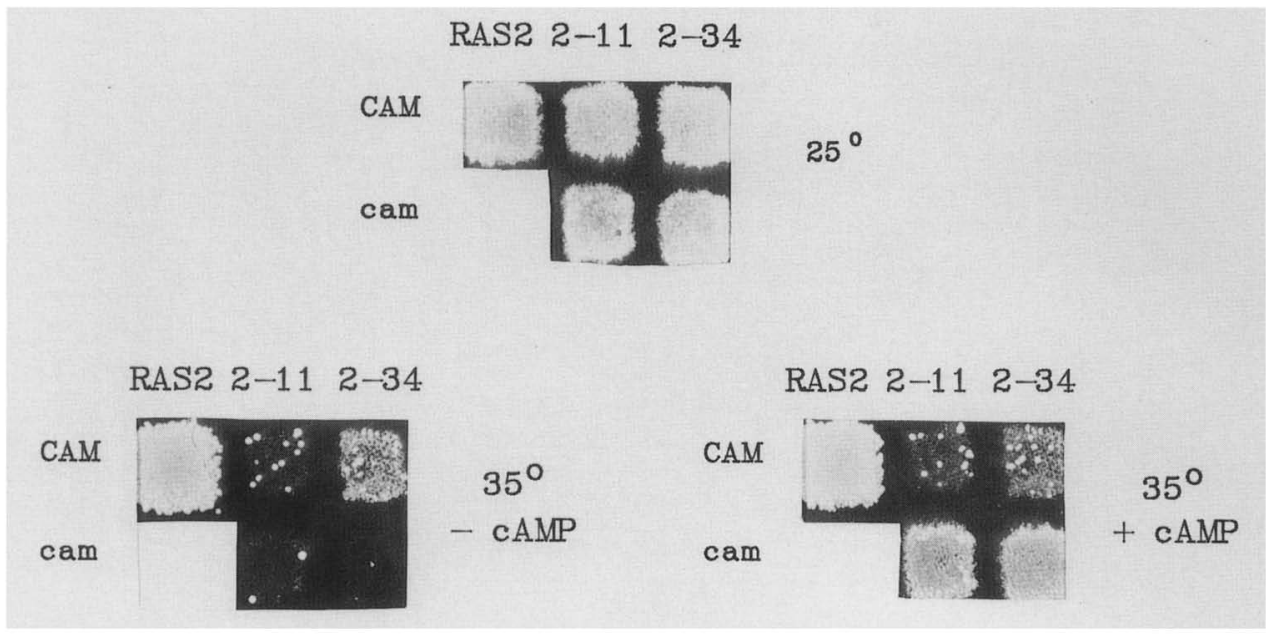

Figure 2. Suppression of $r a s 2^{\text {ts }}$ by cAMP. Growth was tested by replicating patches to agar at $35^{\circ} \mathrm{C}$, with or without exogenous cAMP (100 mM). (CAM) cAMP impermeable; (cam) cAMP permeable. Strains are RAS2 (ras1:: HIS3 RAS2), $2-11$ (ras1 :: HIS3 ras $2^{\text {ts } 11}$ ), $2-34$ (ras1 :: HIS3 ras $^{\text {ts34) }}$ ).

both heat shock and nitrogen starvation than the wildtype $R A S 2^{+} B C Y 1^{+}$strain. Strains of the sra 9 and sra 10 complementation groups also exhibited varying degrees of suppression for temperature-sensitive growth, glycogen accumulation, and sensitivity to stress; however, none of the suppressors conferred phenotypes as extreme as the bcy1 mutations. In contrast, suppression of the pleiotropic ras 1 ras 2 phenotypes by the yak 1 alleles seemed confined to the growth defect because the revertants of that complementation group exhibited healthy growth on several different carbon sources, yet still hyperaccumulated glycogen.

\section{Cloning YAK1}

Because the yak1 suppressors were recessive, the wildtype allele was isolated by complementation from a $S$. cerevisiae library in a low-copy LEU2 CEN4 vector, pSB32 (see Materials and methods). Two revertants containing alleles yak1-39 and yak1-82, respectively, were transformed to $\mathrm{Leu}^{+}$with the plasmid library at the permissive temperature $25^{\circ} \mathrm{C}$. After several days of growth, the transformants were replicated to minimal medium and YEPD and incubated at the permissive and nonper-

Table 2. Spontaneous suppressors

\begin{tabular}{lccc}
\hline Class & Locus & $\begin{array}{l}\text { Frequency } \\
(\%)\end{array}$ & $\begin{array}{l}\text { Ras } \\
\text { independence }\end{array}$ \\
\hline Recessive & yak1 & 10 & + \\
& sra9 & 20 & - \\
& sra10 & 20 & - \\
& byc1 & 5 & + \\
Dominant & unassigned & 35 & ND \\
\hline
\end{tabular}

a RAS independent $(+\mid$ or dependent $(-1$ growth, as measured by germination and growth of a ras $1::$ HIS 3 ras $2:: U R A 3$ spore. (ND) Not determined. missive temperatures. Of $\sim 16,000 \mathrm{Leu}^{+}$colonies tested (8000 from each revertant), 5 regained the temperaturesensitive growth phenotype of the ras1 ras $2^{\text {ts }}$ YAK1 parent.

To confirm that temperature-sensitive growth was a result of the presence of the $L E U 2$ marker, plasmid DNA from each $\mathrm{Leu}^{+}$, temperature-sensitive colony was used as a source of DNA for a second transformation into both ras 1 ras $2^{\text {ts }}$ yak1 revertants. Only three of the five potential clones appeared to confer temperature sensitivity on retransformation (see Fig. 3A). One plasmid (pGS100, Fig. 3B) was isolated as complementing the yak1-39 allele, whereas two others (pGS101 and pGS102) were isolated in the yak1-82 strain. Each plasmid was tested for its ability to complement several different yak 1 alleles, as well as an allele each of the sra 9 and sra 10 complementation groups. All three plasmids complemented each of four yak1 alleles $(18$, 39,79 , and 82 ) but failed to complement the suppressors in the sra9 or sra10 revertants.

To identify the $Y A K 1$-coding region, we constructed a physical map of plasmids pGS100, pGS101, and pGS102. All three plasmids contained the large region of homology shown in Figure 3B. To delineate the regions necessary for yak 1 complementation, several smaller fragments were subcloned into the original LEU2 cloning vector pSB32, as well as a variant of that vector, pGS65 (see Table 1), and tested for their ability to complement the yak1 mutations. The fragments tested, along with the complementation pattern, are shown in Figure 3B. These results suggest that a region between 3300 and 3800 bp appears necessary for full complementation.

To prove that the DNA fragment represented in Figure 3B contains $Y A K 1$ sequences, we showed that it directed an appropriate yeast marker into a region of the chromosome genetically linked to the yak1 suppressors. Plasmid pGS129 (LEU2 YAK1) was integrated into the 

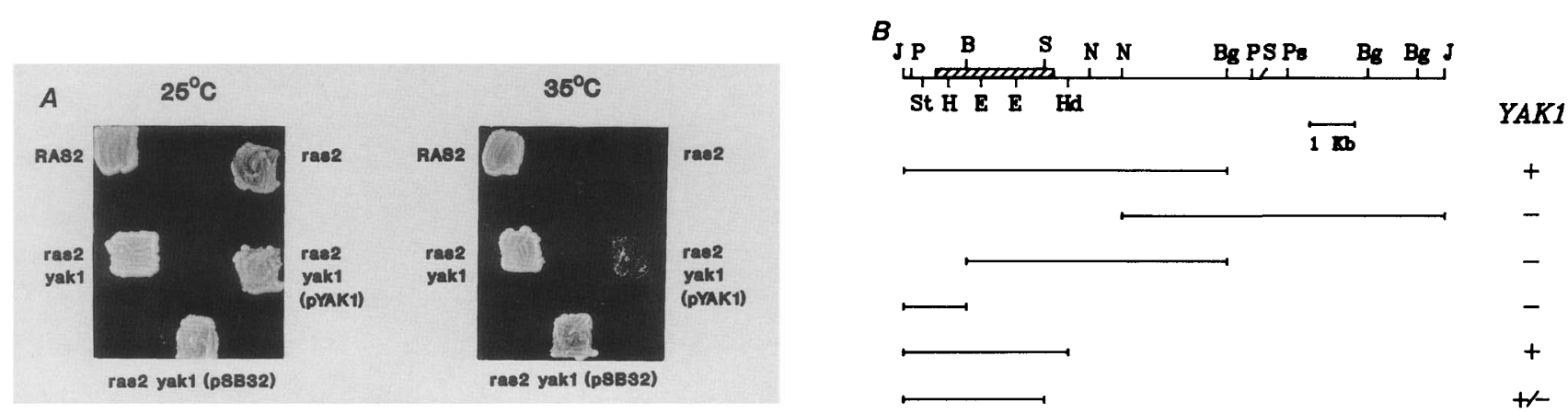

Figure 3. Cloning and restriction map of $Y A K 1$. (A) Strains were patched onto YEPD medium and incubated for 3 or 2 days at $25^{\circ} \mathrm{C}$ and $35^{\circ} \mathrm{C}$, respectively. All strains contain the ras $1:$ : HIS3 mutation and are RAS2 (SGP4), ras2 (SGP34), ras2 yak1 (SGP34 yak1-39), ras2 yak1 (pYAK1) [SGP34 yak1-39 (pGS100)]; and ras2 yak1 (pSB32) [SGP34 yak1-39 (pSB32)]. (B) Solid lines represent different yeast chromosomal fragments (top line represents pGS100) used to test complementation of several yak1 alleles. $(+\mid$ Complementation; ( \pm ), weak complementation; $(-1$, no complementation. (J) Plasmid/yeast chromosomal junction; (P) PvuII; (B) BamHI; (V) EcoRV; (S) SalI; (H) HindIII; (Bg) BglII.

chromosome of strain SGP10 (MATa ras1:: HIS3 ras2 $2^{\text {ts34 }}-U R A 3$ YAK1) through homology with the cloned fragment, and a Leu ${ }^{+}$transformant was crossed with two appropriately marked Yak1 strains (MA-T $\alpha$ ras1::H1S3 ras2 ${ }^{t s}$-URA3 yak 1 -39 and (MA-T $\alpha$ ras1:: H1S3 ras $^{\text {ts }}$-URA3 yak 1-82). Of 50 tetrads containing two $\mathrm{Leu}^{+}$spores, there were 49 parental ditypes, 0 nonparental ditypes, and 1 tetratype. This segregation pattern suggests that the cloned fragments contain the wild-type YAK1 gene rather than DNA that encodes a similar function.

\section{YAKl may encode a protein kinase}

To determine whether YAK1 encodes a product with homology to any proteins found in one of the available data bases, we sequenced the smallest region capable of fully complementing alleles yak1-39 and yak1-82. One long open reading frame (ORF) is found in the $3599 \mathrm{bp}$ sequenced (Fig. 4). The YAK1 gene would encode a protein of 807 amino acids if the first methionine in the ORF is used. An in-frame stop codon is found just 9 nucleotides upstream from that ATG.

The coding region of $Y A K 1$ predicts a protein bearing striking homology with known protein kinases (Table 3). Several amino acid sequences diagnostic for protein kinases are emphasized in Figure 4 (Hanks et al. 1988). The ATP-binding site is thought to include the sequence Gly $X$ Gly $X X$ Gly $X$ Val ( $X$ is any amino acid), followed by an invariant Lys 7-16 amino acids later. This sequence is denoted by stars in Figure 4. Three other sites common to protein kinases are underlined and appear 116 residues downstream from the ATP-binding site: Glu Leu, Asp Phe Gly, and Ala Pro Glu. A computer search of the translated form of GenBank reveals significant homology between the product of YAK1 and the entire protein kinase family (Table 3 ). These results suggest that $Y A K 1$ encodes a protein kinase. Although the predicted kinase domain of $Y A K 1$ exhibits greater identity to some proteins than to others (it appears more related to the products of $c d c 2$ and $C D C 28$ than STE7), none of these homologies would appear sufficient to allow the assignment of the YAK1 product to a particular class of kinases (Hanks et al. 1988). Most significant is the relatively low identity between the catalytic domain of the cAMP-dependent protein kinases and the $\mathrm{ki}$ nase domain predicted for the YAK1 product. This contrasts with the very high degree of identity between the cAPK proteins and the predicted amino acid sequence of a gene $(S C H 9)$ isolated as a high-copy suppressor of a defect in CDC25 (Toda et al. 1988).

One intriguing feature of the predicted amino acid sequence of Yakl is the presence of an extended aminoterminal domain that is distinct from the conserved kinase domain of the protein. This organization is similar to a variety of other protein kinases, such as $s r c$, protein kinase $\mathrm{C}$, and $\mathrm{Sch} 9$, although the actual sequence within this domain is unrelated to any protein in the GenBank data base. This amino-terminal domain encompasses several noteworthy features. A glutamine-rich region is present from amino acid 56 to 85 , including a stretch of 12 consecutive glutamine residues. Similar glutaminerich regions have been observed in SSN6 and GAL11, although a role for this feature has not been identified in either case (Shultz and Carlson 1987; M. Ptashne, pers. comm.). Also found within the amino-terminal domain are a series of four consensus sites for cAPK phosphorylation, $\operatorname{Arg} \operatorname{Arg} X$ Ser (Edelman et al. 1987). Although the function of these sites is unknown, their potential role in regulation of Yakl activity is discussed below.

\section{YAK1 is not essential}

Because yak1 mutations were recessive and relatively common, it seemed likely that suppression of the temperature-sensitive ras defect was a result of the loss of Yakl function. To test this assumption, it was first necessary to determine whether YAK1 was essential. Two different disruptions were constructed on the basis of our knowledge of the YAK1 complementing region (Fig. 3B) and predicted coding sequence (Fig. 4). The first disruption placed the HIS3 gene into the single BamHI 
.793 GATCTTITAAATGCICTCCIACGTICTACAAGAGCTTCTTTGATTACTAACCTGGCTTCACTTAGGTTCAAGGCAATCA

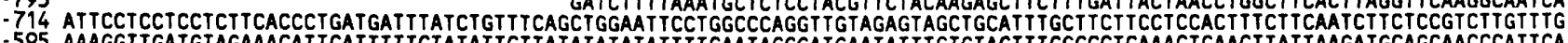

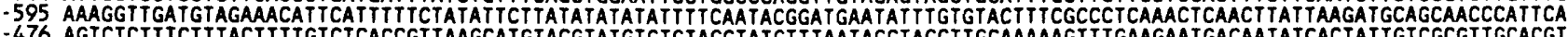
- 76 AGTCTCTITCTITACTITTGTCTCACCGTIAAGCATGTACGTATGTGTGTAGGTATGTITAATAGCTACCT TGCAAAAGTITGAAGATGACAATATCACTAT TGTCGCGITGCACG 35 AAATGACACCTAAAAAGGATT TAGGATITGGAGAAAAAAACTAAAAAAAATATAAAAGGCCTAATAAAAATA I CAAAATAGCGCGATGGCT TIAT TAACCCTAACCGCCCCT TCT GAAC - 238 CATTGCAGCAATGCCCCTCCTCAGATTTACCCCTTCTGGGCTGAACAATGAATGAGTCGCAATGCTAAACAGATATAAGGAAACAATTGGTGGGCATTACTGGGGGTAT TACACAA

1 ATG AAC TCA TCC AAT AAT AAC GAC TCG TCC AGC TCC AAT AGC AAC ATG AAT AAC TCC TTG AGC CCG ACC CTT GTG ACC CAC AGT GAT GCT 1 Met Asn Ser Ser Asn Asn Asn Asp Ser Ser Ser Ser Asn Ser Asn Met Asn Asn Ser leu Ser Pro Thr Leu Val Thr His Ser Asp Ala 91 AGT ATG GGC TCG GGT AGA GCA AGC CCA GAC AAT AGC CAT ATG GGG AGA GGT ATA IGG AAT CCA TCG IAC GTA AAT CAA GGC TCT CAA AGG 31 Ser Met Gly Ser Gly Arg Ala Ser Pro asp Asn Ser His Met Gly Arg gly ile Trp Asn pro Ser Tyr Val Asn Gln Gly Ser Gln Arg

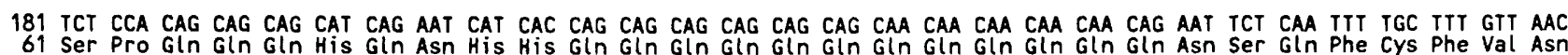
271 CCT TGG AAT GAG GAA AAA GTA ACT AAT TCT CAA CAA AAC CTG GTG TAT CCC CCT CAA TAC GAT GAC TTA AAC AGT AAC GAA AGT CTA GAT

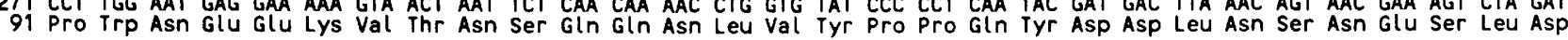
361 GCG TAC AGA CGA CG AAA TCT AGT CTC GTT GTA CCT CCA GCC AGG GCA CCT GCC CCA AAT CCT TTC CAG TAC GAT AGT TAT CCC GCT TAC 121 Ala tyr Arg arg arg lys Ser Ser leu Val Val Pro pro ala arg ala Pro ala Pro asn pro phe gln tyr asp Ser tyr pro ala tyr 451 ACC AGC TCT AAT ACG AGT TTG GCA GGA AAT AGC AGT GGC CAG TAT CCT TCT GGC TAT CAA CAA CAA CAA CAG CAA GTA TAC CAG CAG GGC $151 \mathrm{thr}$ Ser ser Asn thr Ser Leu Ala Gly Asn Ser Ser Gly Gln tyr Pro ser Gly Tyr Gin Gln Gln Gln Gln Gin Val Tyr Gln Gln Gly 541 GCT ATC CAT CCT TCC CAA ITT GGA TCC AGA TIT GTT CCC TCC CIT TAT GAT CGT CAA GAT ITC CAA AGA AGG CAG AGT CTG GCT GCA ACT 181 Ala Ile His Pro Ser Gln phe Gly Ser Arg Phe Val Pro Ser Leu Tyr Asp Arg Gln Asp phe Gln arg Arg Gln Ser Leu Ala Ala Thr

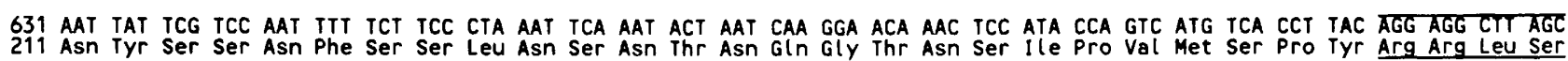
721 GCA TAT CCT CCT AGT ACA AGT CCC CCA CTA CAA CCC CCT TIC AAG CAG ITA CGA AGA GAT GAA GTA CAA GGT CAG AAA TTG TCC ATT CCT
241 Ala Tyr Pro Pro Ser Thr Ser Pro Pro Leu GIn Pro Pro phe Lys GIn Leu Arg Arg Asp Glu Val Gln Gly Gln Lys Leu Ser Ile Pro

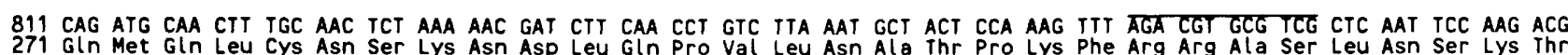
901 ATA TCT CCC CTA GTC AGT GTC ACG AAA AGC CTG ATT ACC ACA TAT TCT TTA TGT TCT CCA GAA TIT ACC TAC CAA ACG TCC AAA AAC CCC 991 AAG AGA GTA CTT ACG AAG CCC AGT GAA GGG AAA TGT AAC AAC GGA TTC GAC AAC ATA AAC AGT GAC TAT ATT CTT TAT GTA AAT GAC GTT 331 Lys Arg Val Leu thr lys pro ser Glu Gly Lys Cys Asn Asn Gly phe Asp asn ile asn Ser asp tyr ile Leu tyr Val Asn Asp Val 1081 TTG GGT GTA GAG CAG AAC AGA AAG TAC CTT GTG CTA GAC ATT TTG GGT CAA GGT ACA TIT GGT CAA GTG GTC AAA TGT CAA AAT TTG CTG 361 Leu Gly Val Glu Gln Asn Arg Lys Tyr leu val leu Asp Ile leu Gly Gln Gly thr phe Gly Gln Val Val Lys Cys Gln Asn Leu Leu 1171 ACG AAA GAG ATA TTG GCT GTA AAA GTG GTT AAA TCG AGG ACA GAA TAT TTG ACT CAA AGT ATA ACG GAG GCT AAA ATT ITA GAG CTA CTG 391 Thr Lys Glu ile Leu Ala val lys Val Val Lys Ser arg thr Glu tyr leu Thr Gin Ser Ile thr Glu Ala Lys Ille Leu Glu Leu Leu 1261 AAT CAA AAG ATA GAC CCT ACT AAT AAA CAT CAT TIT ITA AGG ATG TAT GAC TCC ITT GIC CAC AAG AAC CAC ITA TGT ITA GTG ITT GAA 421 Asn Gln Lys Ile Asp pro thr Asn lys his his phe Leu Arg Met tyr asp ser phe val his Lys Asn his Leu Cys Leu Val phe Glu

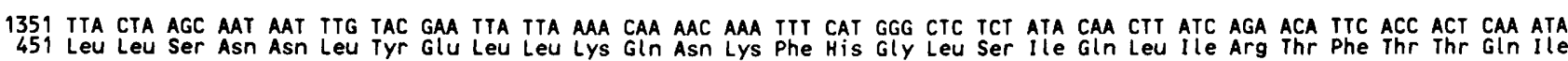
1441 CTG GAT TCG TTA TGC GTT TTG AAG GAA AGC AAA CTG ATT CAT TGC GAT CTG AAG CCA GAG AAT ATC ITG CTC TGC GCA CCT GAT AAG CCG

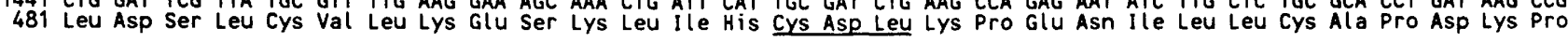
1531 GAA ITG AAA ATT ATT GAT ITT GGC ICA TCT TGC GAA GAG GCA AGA ACC GIT TAT ACA TAC ATC CAG TCC AGG TIT TAT CGT GCT CCT GAA 1621 ATT ATA CTG GGT ATA CCG TAT TCA ACC AGT ATT GAC ATG TGG TCG TTA GGT TGT ATT GTT GCT GAA ITA TIT TTG GGT ATA CCG ATC ITC 1711 CCA GGC GCT TCT GAA IAT AAC CAA TIA ACA AGA ATA ATA GAC ACG CTT GGA TAT CCT CCA TCG TGG ATG ATA GAT ATG GGT AAA AAC TCT 571 pro gly ala Ser Glu tyr Asn gln leu thr Arg Ile Ile Asp thr leu gly tyr Pro pro ser trp Met ile asp Met Gly Lys Asn Ser

1801 GGA AAA TIT ATG AAG AAA ITG GCA CCA GAA GAA AGT TCT TCT TCT ACA CAA AAG CAT CGT ATG AAA ACT ATT GAA GAG TTT TGC AGA GAA

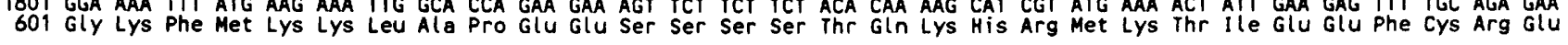
1891 TAC AAT ATA GTG GAA AAG CCC AGT AAA CAA TAT TTT AAG TGG AGA AAG TTA CCA GAT ATT ATT AGA AAC TAC AGG TAT CCT AAA AGC ATA 631 Tyr Asn Ile val Glu lys pro Ser Lys gln tyr phe Lys trp arg lys leu pro asp ile Ile Arg Asn tyr Arg tyr pro lys Ser Ile 1981 CAG AAC TCC CAA GAA CIT ATC GAC CAA GAA ATG CAG AAT AGG GAG TGT TTG ATC CAC ITT TTA GGC GGT GTG CTA AAT TTG AAC CCG ITA

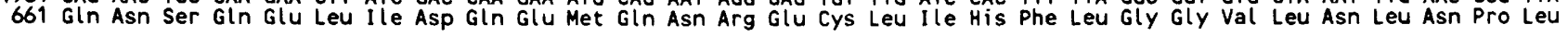
2071 GAA AGA TGG ACA CCA CAA CAA GCT ATG CTA CAC CCC ITC ATA ACA AAG CAG GAG TTT ACA GGT GAG TGG ITT CCT CCA GGA TCG TCT TTA
691 Glu Arg TrP Thr Pro Gln Gln Ala Met Leu His Pro Phe Ile Thr Lys Gln Glu Phe thr Gly Glu trp Phe Pro Pro Gly Ser Ser Leu 2161 CCG GGT CCT TCA GAA AAA CAT GAC GAT GCA AAA GGC CAG CAA AGT GAA TAT GGA AGT GCG AAC GAC TCT AGT AAC AAT GCA GGC CAC AAC 2251 TAT GTC TAT AAT CCT AGC TCT GCC ACT GGT GGT GCT GAT AGC GTC GAC ATT GGT GCT ATC AGT AAA AGG AAG GAG AAT ACA TCT GGC GAC 751 Tyr Val tyr Asn Pro Ser Ser Ala thr Gly Gly Ala Asp Ser val asp ile Gly ala Ile Ser Lys arg Lys Glu Asn thr Ser Gly asp 2341 ATC TCC AAT AAT TIT GCT GIT ACT CAT ICT GIT CAA GAA GGG CCA ACA AGC GCG TTC AAT AAA CTT CAC ATT GTC GAA GAA TAA ATCGTTA 781 Ile Ser asn Asn phe Ala Val thr his Ser Val GIn Glu Gly Pro thr Ser ala phe Asn Lys Leu his ile val Glu Glu ...

2432 TITIGTCTGACTITTCTTAACTACCCATITCATTTIATTACGGCTTGGTGCCATAATGATATACTAAATAAATATGAATTTGGCCCTITTCTTAATITTCCTTATACGTATAAGTCATT 2551 ACAATTAATAAAAGTAACAT TATAAAAGTTCTGCACTAGCT TTGGCT TGT TGATATTTCTCT TCAGAGATGAAGTATGGTACTTT TCAATATATAATATGTACATGGT TGAGAGA 2670 AATGGTTGGTAATCTTGAAATAAAA
2789 AAAAAATGGCTCATATAATGTC

Figure 4. Nucleotide and predicted amino acid sequence of $Y A K 1$. The nucleotide sequence extends $3599 \mathrm{bp}$ from the YCp50-yeast DNA junction to the HindIII site in Fig. 3B. Sequences conserved in protein kinases are indicated by stars (ATP binding) or by underlining (catalysis). The termination codon is represented by hyphens. Putative sites of cAPK phosphorylation are denoted by overlines and underlines. 
Table 3. Protein kinase homologies

\begin{tabular}{lccl}
\hline Protein kinase & $\begin{array}{l}\text { Optimized } \\
\text { score }^{\mathbf{a}}\end{array}$ & $\begin{array}{l}\text { Percent } \\
\text { identity }^{\mathrm{b}}\end{array}$ & Reference \\
\hline Schizosaccharomyces pombe cdc2 & 349 & 32 & Hindley and Phear (1984) \\
S. cerevisiae CDC28 & 288 & 31 & Lorincz and Reed (1984) \\
Mouse phosphorylase kinase $(\gamma)$ & 245 & 23 & Chamberlain et al. (1987) \\
Mouse cAPK & 197 & 20 & Uhler et al. (1986) \\
STE7 & 156 & 24 & Teague et al. (1986) \\
\hline
\end{tabular}

a Optimized score, as determined by the FASTP program (Lipman and Pearson 1985).

b Percent amino acid identity over a stretch of 250-300 residues encompassing the putative kinase domain.

site of the coding region, so that only the first 189 amino acids would be expressed from the endogenous promoter. A second disruption removed all of the kinase domain between EcoRV sites at nucleotides 842 and 1702 and replaced it with the LEU2 marker. Both disruptions were shown to inactivate Yakl function in a complementation test similar to the one used in the subcloning experiments (Fig. 3A; data not shown). Each disruption was transplaced into diploid strain 1029, and two independent heterozygous YAK1/yak1 diploids from each transformation were sporulated and scored. The disruptions segregated $2: 2$, as judged by the His and Leu phenotypes of the resulting colonies. Two tetrads from each diploid were checked by hybridization analysis, and in each case, the presence of the selectable auxotrophic marker correlated with the shift in fragment size expected for the disrupted allele (data not shown). Because the HIS3 insertion was within the amino terminus of the protein and the LEU2 marker displaced all of the putative kinase domain, we assume that at least one of these disruptions represents a complete loss of function. Thus, the Yak1 gene is not essential for growth or germination.

\section{Physiology of the yak 1 strains}

Because none of the spontaneous yak1 mutations suppressed the glycogen hyperaccumulation by the ras $2^{\text {ts }}$ strains, we tested several wild-type strains containing either of two yak1 disruptions for phenotypes related to those exhibited by other mutants of the Ras/cAMP pathway. Several yak1 colonies were examined for heat shock sensitivity, glycogen accumulation, sensitivity to nitrogen starvation, and sporulation defects. All of the yak1 strains appeared wild type for nitrogen starvation and heat shock sensitivity, as well as glycogen accumulation (see Fig. 5B) and sporulation competence. To make certain the phenotype conferred by the disruptions was the same as that conferred by the original suppressors, several spontaneous alleles (yak1-39, yak1-79, and yak1-82) were moved into a wild-type RAS2 background by the crosses outlined in Materials and methods. Once again, the RAS2 yak1 strains appeared as wild type, although a slight alteration might not be detected by these assays.
Loss of the Yakl kinase suppresses ras $2^{\text {ts }}$ and tpk mutations

To determine whether suppression of the temperaturesensitive ras defect was a result of the loss of Yakl function, the yak1::LEU2 disruption (Materials and methods) was transplaced into strains SGP11 and SGP34 (ras1 :: HIS3 ras2-11-URA3 and ras1 :: HIS3 ras2-34$U R A 3$, respectively) by selecting for growth on minimal medium at $25^{\circ} \mathrm{C}$. Four Leu ${ }^{+}$colonies from each transformation were tested for growth at the nonpermissive temperature. In all cases, transplacement conferred temperature resistance. Thus, suppression of the ras defect appeared to be a result of the loss of Yakl function. To determine the point of Yakl action in the Ras/cAMP pathway, tests of epistasis were performed on the mutant strains listed in Table 4 . All of the strains exhibiting conditional growth, including those carrying temperature-sensitive mutations in ras2, cdc25, and cyr1, reverted to nonconditional growth on transplacement with the yak1 disruptions.

Although the growth defect of strain 460 (cyr1-2) was suppressed by both yak1 disruptions (Table 4), it was possible that suppression was dependent on residual cyclase activity or functioned immediately downstream from Cyrl. Therefore, we determined whether either disnuption could suppress the complete loss of Ras or cAPK activity. Heterozygous ras and tpk diploids (SGP9 and S7-7A $\times$ S7-5A) were transformed to $\mathrm{Leu}^{+}$with the yak1 :: LEU2 disruption, sporulated, and picked onto synthetic complete-minimal glucose agar. Haploid spores containing ras1 ras2 or tpk1 tpk2 tpk3 disruptions failed to germinate (as judged by segregation of the auxotrophic markers) unless they contained the mutant yak1 allele. Figure 5A shows the growth of spores from several tetrads of a yak1 :: LEU2 transformant of diploid strain S7-7A $\times$ S7-5A. The large colonies contained at least one wild-type TPK gene, and the tiny colonies bore disruptions of all three TPK genes and the LEU2 marker indicative of the yak1 disruption. For each tetrad resulting in growth of only two or three colonies, segregation of the auxotrophic markers predicted that the spores that failed to germinate contained all three tpk disruptions and the wild-type YAK1 allele.

It is apparent from Figure $5 \mathrm{~B}$ that although the tpk yak1 strains are viable, they are compromised for 

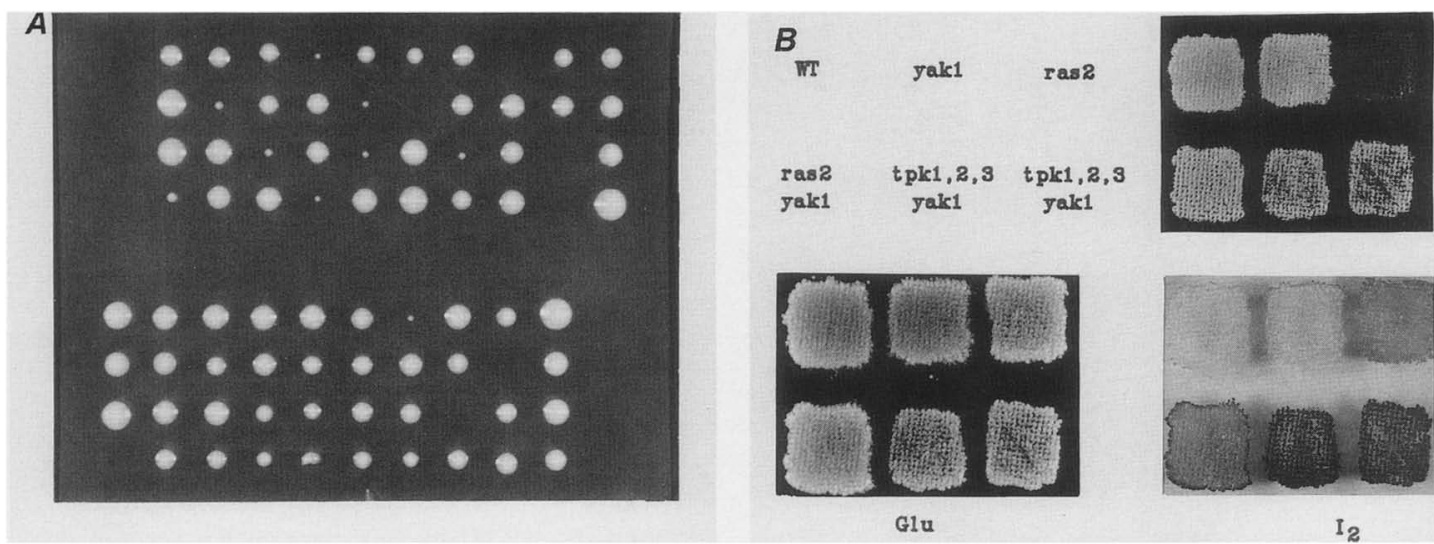

Et OH

Figure 5. Suppression of ras and tpk mutations by yak1. (A) Diploid strain S7-7A $\times$ S7-5A |MATa/MATa TPK1/tpk1:: URA3 TPK2/ tpk2 :: HIS3 TPK3/tpk3 :: TRP1 leu2/leu2) was transformed to Leu ${ }^{+}$with the yak1 :: LEU2 disruption and tetrads were dissected and scored on the appropriate minimal medium agar to determine the segregation of the tpk and yak 1 disruptions. All of the small colonies contained disruptions of the three tpk genes, as well as the yak1 ::LEU2 mutation. (B) Strains indicated at top left are WT (SGP4), yak1 (SGP400), ras2 (SGP430), ras2 yak1 (SGP431), tpk1,2,3 yak1 (SGP406), tpk1,2,3 yak1 (SGP432). Patches of these strains were replicated to rich medium containing EtOH/glycerol (top right) or glucose (bottom right and bottom left) as the carbon source. (Bottom right) patches were scored for glycogen accumulation by inverting them over $\mathrm{I}_{2}$ vapors, as outlined in the text.

growth and hyperaccumulate glycogen. This latter phenotype is not simply the result of the slow growth of these strains, because a Ras1 ras2 strain exhibits wildtype growth on glucose medium but hyperaccumulates glycogen regardless of the YAK1 allele (YAK1 or yak1 :: LEU2) (Fig. 5B).

\section{Discussion}

By isolating revertants of a $S$. cerevisiae strain deficient in the Ras/cAMP pathway, we identified at least one new locus (YAK1), whose product may be involved in cell-cycle regulation. This locus was defined by a recessive complementation group isolated as a suppressor of the conditional-growth defect of several temperaturesensitive ras mutants. Three other genes also were identified in the screen. One corresponds to the previously isolated BCY1 gene (Cannon and Tatchell 1987; Kunisawa et al. 1987; Toda et al. 1987a) and one may be al- lelic to PDE2 (Sass et al. 1986; Wilson and Tatchell 1988). Thus, at least one, and possibly two, additional novel genes involved in the Ras/cAMP pathway have emerged from this analysis.

The most interesting result from these studies is that disruptions of $Y A K 1$ suppress the cell-cycle defect of a strain deleted for all three TPK genes. This makes YAK1 the only gene whose loss of function has been shown to suppress the growth defect of a tpk deletion strain. This result is somewhat paradoxical because the YAK1coding region predicts a protein kinase of 807 amino acids. Thus, the loss of function of three kinase proteins is alleviated by the loss of yet another kinase. This situation contrasts with that for suppression of $t p k$ by $\mathrm{SCH}$. SCH9 also encodes a protein kinase, exhibiting significant homology with the CAPK catalytic subunits (Toda et al. 1988/. However, overexpression of $\mathrm{SCH}$, not its elimination, suppresses tpk. Given the sequence similarities of Sch9 and the cAPK subunits, suppression of a

Table 4. Epistasis studies with several yakl disruptions

\begin{tabular}{|c|c|c|c|c|}
\hline \multirow[b]{2}{*}{ Strain } & \multirow[b]{2}{*}{ Suppressor } & \multicolumn{2}{|c|}{ Glucose } & \multirow[b]{2}{*}{$\mathrm{EtOH}^{2}$} \\
\hline & & $\overline{25^{\circ} \mathrm{C}}$ & $35^{\circ} \mathrm{C}$ & \\
\hline \multirow[t]{2}{*}{ ras1 $::$ HIS3 ras2 $2^{\mathrm{ts} 34}$} & $Y A K 1^{+}$ & + & - & - \\
\hline & yak1 :: LEU2 & + & + & + \\
\hline \multirow[t]{2}{*}{$R A S 1+\operatorname{ras} 2:: L E U 2$} & $Y A K 1^{+}$ & + & + & - \\
\hline & yak1 :: HIS3 & + & + & + \\
\hline \multirow[t]{2}{*}{ cyr $1-1$} & $Y A K 1^{+}$ & + & - & - \\
\hline & yak1 :: LEU2 & + & + & + \\
\hline \multirow[t]{2}{*}{$c d c 25-1$} & $Y A K 1^{+}$ & + & - & - \\
\hline & yak1 :: LEU2 & + & + & + \\
\hline \multirow[t]{2}{*}{ ras $1::$ HIS 3 ras $2::$ URA3 } & $Y A K 1^{+}$ & - & - & - \\
\hline & yak1 :: LEU2 & \pm & \pm & \pm \\
\hline \multirow[t]{2}{*}{ tpk1 tpk2 tpk3 } & $Y A K 1^{+}$ & - & - & - \\
\hline & yak1 :: LEU2 & \pm & \pm & \pm \\
\hline
\end{tabular}

a + | Growth; $1-\mid$ no growth; $| \pm|$ slow growth. 
tpk strain by overexpression of $\mathrm{SCH} 9$ most likely occurs as a result of overlapping specificity of the two kinases. Such an explanation clearly does not account for yak1 suppression of $t p k$.

The roles of Sch9 and Yakl in the Ras/cAMP pathway are still not understood. Available evidence would suggest that Sch9 might be on a parallel pathway (Toda et al. 1988|. Although we have not eliminated the possibility that Yakl is also part of a parallel pathway, our results are consistent with a model in which Yakl is a $\mathrm{G}_{1}$-specific inhibitor of the cell cycle, and it, in turn, is regulated negatively by cAPK activity. According to this model, strains exhibiting decreased CAPK activity, such as a tpk deletion mutant, would fail to grow because Yak1 would actively block cell-cycle progression. Growth would be restored to these strains by mutations in YAK1 that result in its loss of function. Although Yak1 could be regulated by cAPK activity in an indirect manner, it is tempting to speculate that one or more of the cAPK consensus sites within the amino terminus of Yakl is phosphorylated in vivo. In this scenario, phosphorylation of Yak1 would lead to its inactivation and alleviation of its inhibition of cell-cycle progression.

An intriguing feature of the yak 1 mutations, including the disruptions, is that they do not revert all of the phenotypes associated with diminished CAPK activity. For example, loss of Yakl function restores growth to strains with defects at different points in the Ras/cAMP pathway yet does not alter their propensity to accumulate glycogen. Moreover, a strain deficient only in Yak1 activity exhibits wild-type glycogen stores and is resistant to heat shock and nitrogen starvation. The simultaneous reversion of several phenotypes conferred by a primary defect is often used as indirect proof that the suppressor mutation defines a function integral to the pathway under study. Although this reasoning often proves correct, it is probably wrong to assume that all suppressors within a pathway must revert all of the phenotypes associated with the original defect. This is particularly true for genes whose products act beyond a point of divergence in the pathway. Because the initial selection was for reversion of the Ras- growth defect, we reasoned that suppressors of the temperature-sensitive growth arrest would be interesting even if other phenotypes associated with the loss of RAS function were not alleviated similarly. Thus, the failure of mutations in yak1 to revert all of the Ras ${ }^{-}$associated phenotypes can be reconciled with a role for Yakl in the Ras/ cAMP pathway if Yakl acts beyond the phosphorylation/dephosphorylation branch point. Our epistasis results support this conclusion. In addition, the assignment of Yakl to only one branch in the pathway might account for the rather slow growth of tpk deletion strains containing the yak1 suppressors. These strains would remain compromised for all other metabolic functions regulated by cAPK phosphorylation, including carbohydrate storage and utilization (Uno et al. 1983b).

Our model for the role of Yakl is tentative; however, it makes several predictions that can be tested. First, as a negative regulator of cell growth, the Yakl protein might be expected to be dispensable for viability. Because disruptions of both the amino- and carboxy-terminal (kinase) domains of Yakl result in cell viability, it seems likely that YAK1 is a nonessential gene. Second, enhanced Yakl activity, perhaps by overproduction, should result in the same cell-cycle arrest observed in strains deficient in CAPK activity. Although strains containing $Y A K 1$ on a high-copy plasmid do not grow appreciably slower than strains carrying the vector alone /S. Garrett and J. Broach, unpubl.), a conclusion about this prediction must await its placement under control of an inducible promoter. Finally, the model suggests that Yakl is regulated negatively by cAPK activity and that Yak1 activity is determined by its state of phosphorylation. Further characterization of YAK1 and its product should be helpful in determining the answers to these questions.

In contrast to the limited suppression pattern conferred by the yak1 mutations, suppressors from the complementation group sra9 and sra10 revert all of the pleiotropic $\mathrm{Ras}^{-}$phenotypes, albeit to degrees consistent with a hierarchy of suppressor strength. According to these criteria, the $s r a 9$ and sra10 suppressors most resemble mutations in bcy1, which are also pleiotropic. The pattern of suppression by the bcy 1 alleles is consistent with a role for its product upstream of the branch point in the Ras/cAMP pathway (defined by the state of phosphorylation of a variety of cellular substrates). Molecular characterization of $\mathrm{BCY} 1$ has shown this to be true (Cannon and Tatchell 1987; Toda et al. 1987a). Although we have no molecular evidence for the product of SRA9 or sra10 affecting the phosphorylation state of the cellular substrates, the pattern of suppression is consistent with this assumption. Such roles might include a protein that functioned as an intermediate in the feedback mechanism attenuating cAMP production (Nikawa et al. 1987b; Resnick and Racker 1988) or a protein phosphatase activity that counteracts cAPK activity (Wingender-Drissen and Becker 1983; Matsumoto et al. 1985 ). Further evaluation should allow us to pinpoint the role of these genes in the pathway.

\section{Materials and methods}

Strains and plasmids

All yeast strains are listed in Table 1. Bacterial strains MC1066 [S|lac|X74 galU galK strA ${ }^{\mathrm{r}}$ hsdR trpC9830 leuB6 pyrF :: Tn5] and JM101 [ $\Delta$ (lac-pro)supE thi/F' traD36 proAB IacI $Z \Delta M 15]$ were used for construction and growth of all plasmids, and phage and have been described (Messing et al. 1981; Casadaban et al. 1983). Phage mpll and mpl8 (Messing 1983) were used for the generation of single-stranded DNA for sequencing. The LEU2-based CEN4 vector $\mathrm{p} S \mathrm{~B} 32$ was constructed by J. Truehart by deleting the $U R A 3$ gene from YCp50 and replacing it with LEU2. The $S$. cerevisiae library constructed with this vector was the gift of P. Hieter (The Johns Hopkins University). Plasmid pRJ520-1 (Deschenes and Broach 1987) consists of the $3-\mathrm{kb}$ EcoRI-HindIII Ras2 fragment into which the $1.1-\mathrm{kb}$ $U R A 3$ fragment has been inserted 150 bp past the RAS2 termination codon. Plasmids Yep13-BCY1, ppde1:: LEU2, and ppde2 :: URA3 are from Mike Wigler and have been described 
(Sass et al. 1986; Nikawa et al. 1987ba; Toda et al. 1987a). The YAK1-disruption plasmid pGS130-2 was constructed by inserting the $1.7-\mathrm{kb}$ BamHI fragment of HIS3 into the single BamHI site of Yak1 on pGS100. Plasmid pGS136-A was constructed by inserting the $2.5 \mathrm{~kb}$ BamHI-SalI YAK1 fragment into the corresponding sites of pUC8, dropping out the $600-\mathrm{bp}$ EcoRV fragment within YAK1 (Fig. 3B), attaching XhoI linkers, and inserting the $2.2 \cdot \mathrm{kb}$ SalI-XhoI fragment carrying LEU2. Mapping plasmid pGS129 was constructed by inserting the 6-kb PvuII fragment carrying YAK1 into the integrating LEU2 vector CV03 (Broach and Hicks 1980).

\section{DNA manipulations}

Plasmid DNA was prepared from E. coli using the alkali lysis method (Maniatis et al. 1982). Yeast DNA, plasmid and chromosomal, was prepared according to the method of Nasmyth (Nasmyth and Reed 1980). All enzymes were used according to the specifications of their suppliers (New England Biolabs), and cloning techniques were as described (Maniatis et al. 1982). Hybridizations of yeast DNA were performed as described (Maniatis et al. 1982), except for the substitution of Church buffer (Church and Gilbert 1984).

\section{DNA sequencing}

Overlapping fragments were cloned into the M13 derivatives mpll and mpl8 and used as substrates for single-strand dideoxy sequencing (Sanger et al. 1977) with $\alpha^{-35}$ S-labeled dATP as radioactive label. The 3599 nucleotides shown in Figure 4, from the HindIII site to the junction between yeast DNA and YCp50, were determined by sequencing both strands.

\section{Genetic techniques and media}

Transformation of yeast was by the lithium acetate method (Ito et al. 1983), and other yeast genetic manipulations were performed as described (Sherman et al. 1986). Glycogen staining was scored in situ by inverting a plate over $\mathrm{I}_{2}$ crystals (Deschenes and Broach 1987). Nitrogen-poor medium contained $0.17 \%$ yeast nitrogen base without ammonium sulfate or amino acids (Difco) and $2 \%$ glucose. Determination of survival of the revertants to nitrogen starvation and heat treatment was performed as described (Cannon et al. 1986; Sass et al. 1986). Sporulation efficiency was scored essentially as outlined (Toda et al. 1985). All media, including yeast-rich and minimal media, as well as bacterial media, were prepared as described previously (Deschenes and Broach 1987).

\section{Isolation of ras2 temperature-sensitive alleles}

Hydroxylamine mutagenisis of the RAS2 plasmid pRJ520-1 was carried out for $30 \mathrm{hr}$ at $37^{\circ} \mathrm{C}$, following published procedures (Rose and Fink 1987). The mutagenized plasmid DNA was digested to completion with EcoRI and HindIII and used to transform competent cells of strain SGP3 to $\mathrm{Ura}^{+}$at $25^{\circ} \mathrm{C}$. After several days, the Ura ${ }^{+}$transformants were replicated to $25^{\circ} \mathrm{C}$ and $35^{\circ} \mathrm{C}$ on rich medium (YEPD), as well as minimal medium. Colonies that grew at the lower temperature were selected only as potential ras2 ${ }^{\text {ts }}$ strains.

\section{Selection of ras revertants}

Individual colonies from two MATa ras1 :: HIS3 ras2 $^{\text {ts }}$ strains, SGP11 and SGP34, were patched to YEPD medium agar and incubated for $48 \mathrm{hr}$ at $35^{\circ} \mathrm{C}$. From those patches on which colo- nies arose, a single colony was selected and purified at $25^{\circ} \mathrm{C}$ on YEPD. Potential revertants were then retested for growth at $25^{\circ} \mathrm{C}$ and $35^{\circ} \mathrm{C}$ on rich medium agar, using $2 \%$ glucose, $2 \%$ galactose, or $2 \% \mathrm{EtOH} / 2 \%$ glycerol as carbon source. Over 120 revertants were isolated from each strain. In addition, 30 temperature-resistant revertants were isolated from a $M A$ Ta ras $1::$ HIS3 ras $^{\text {ts }}$ strain (SGP10) to enable complementation tests of the revertants.

\section{Complementation analysis of the revertants}

The temperature-resistant revertants of the $\alpha$ strains SGP1l and SGP34 were mated to their a counterparts by selecting for prototrophic growth. Individual $\alpha$ strains, along with their temperature-sensitive parents and the $\mathrm{RAS2}^{+}$strain SGP4, were patched to YEPD agar, incubated for several days at $25^{\circ} \mathrm{C}$, and then replica-plated to a lawn of the appropriate a revertant on minimal medium. After several days of prototrophic selection at $25^{\circ} \mathrm{C}$, diploids were tested for growth at $35^{\circ} \mathrm{C}$ on YEPD medium. Complementation between recessive alleles was indicated by lack of growth at the nonpermissive temperature.

\section{Crossing the yak1 mutations into a RAS2 strain}

Several yak1 alleles were moved into a RAS2 background by crossing the respective revertants with the $M A$ Ta ras $1::$ HIS 3 RAS2 $^{+}$strain SGP40. Tetrads that exhibited two temperature-sensitive colonies coincident with the presence of the URA3 marker (ras2ts34 $-U R A 3$ ) were assumed to be nonparental ditype, and the Ura- $\left(R A S 2^{+}\right)$colonies were examined for such phenotypes as heat shock sensitivity, glycogen accumulation, sensitivity to nitrogen starvation, and sporulation defects by the procedures outlined in Materials and methods. The RAS2+ colonies were tested for the presence of suppressor alleles by backcrossing them to a ras $1::$ HIS3 $\operatorname{ras}^{\text {ts } 34}::$ LEU2 strain, sporulating the diploids, and testing the tetrads for growth at the nonpermissive temperature. Whereas a wild-type ras1 :: HIS $3 R A S 2^{+} Y A K 1^{+}$strain generated tetrads containing only two temperature-resistant colonies, the ras1 :: HIS3 RAS2+ yak1 strains led to the appearance of two, three, and four temperature- resistant colonies within a tetrad.

\section{Acknowledgments}

We thank Mike Wigler for the generous gift of the yeast disnuption plasmids used in the construction of several strains integral to the complementation analysis. Phil Hieter kindly sent us a sample of his LEU2 CEN4 yeast library for the cloning of $Y A K 1$. Finally, the following people provided both encouragement and helpful suggestions: Bob Deschenes, Sara Jones, Mark Rose, and Tom Silhavy. S.G. was supported by a Fellowship from the Anna Fuller Fund. This work has been supported, in part, by grant CA-41086 from the National Institutes of Health.

\section{References}

Boutelet, F., A. Petitjean, and F. Hilger. 1985. Yeast $c d c 35$ mutants are defective in adenylate cyclase and are allelic with cyr1 mutants while CAS1, a new gene, is involved in the regulation of adenylate cyclase. EMBO J. 4: 2635-2641.

Breviario, D., A. Hinnebusch, J. Cannon, K. Tatchell, and R. Dhar. 1986. Carbon source regulation of RAS1 expression in Saccharomyces cerevisiae and the phenotypes of ras2cells. Proc. Natl. Acad. Sci. 83: 4152-4156. 
Broach, J.R. and J.B. Hicks, 1980. Replication and recombination functions associated with the yeast plasmid, $2 \mu$ circle. Cell 21: 501-508.

Broek, D., T. Toda, T. Michaeli, L. Levin, C. Birchmeier, M. Zoller, S. Powers, and M. Wigler. 1987. The S. cerevisiae $C D C 25$ gene product regulates the Ras/adenylate cyclase pathway. Cell 48: 789-799.

Camonis, J.H., M. Kalekine, G. Bernard, H. Garreau, E. BoyMarcotte, and M. Jacquet. 1986. Characterization, cloning and sequence analysis of the $C D C 25$ gene which controls the cyclic AMP level of Saccharomyces cerevisiae. EMBO I. 5: $375-380$.

Cannon, J. and K. Tatchell. 1987. Characterization of Saccharomyces cerevisiae genes encoding subunits of cAMP-dependent protein kinase. Mol. Cell. Biol. 7: 2653-2663.

Cannon, J.F., J.B. Gibbs, and K. Tatchell. 1986. Suppressors of the ras2 mutation of Saccharomyces cerevisiae. Genetics 113: $247-264$.

Casadaban, M.J., A. Martinez-Arias, S.K. Shapiro, and J. Chou. 1983. $\beta$-Galactosidase gene fusions for analysing gene expression in Escherichia coli and yeast. Methods Enzymol. 100: $293-308$.

Casperson, G.F., N. Walker, and H.R. Bourne. 1985. Isolation of the gene encoding adenylate cyclase in Saccharomyces cerevisiae. Proc. Natl. Acad. Sci. 82: 5060-5063.

Cherry, J.R., T.R. Johnson, C. Dollard, J.R. Shuster, and C.L. Denis. 1989. Cyclic AMP-dependent protein kinase phosphorylates and inactivates the yeast transcriptional activator ADR1. Cell 56: 409-419.

Church, G.M. and W. Gilbert. 1984. Genomic sequencing. Proc. Nat1. Acad. Sci. 81: 1991-1995.

Defeo-Jones, D., E.M. Scolnick, R. Koller, and R. Dhar. 1983. ras-Related gene sequences identified and isolated from Saccharomyces cerevisiae. Nature 306: 707-709.

Deschenes, R.J. and J.R. Broach. 1987. Fatty acylation is important but not essential for Saccharomyces cerevisiae RAS function. Mol. Cell. Biol. 7: 2344-2351.

De Vendittis, E., A. Vitelli, R. Zahn, and O. Fasano. 1986. Suppression of defective RAS1 and RAS2 functions in yeast by an adenylate cyclase activated by a single amino acid change. EMBO /. 5: 3657-3663.

Edelman, A.M., D.K. Blumenthal, and E.G. Krebs. 1987. Protein serine/threonine kinases. Annu. Rev. Biochem. 56: 567613.

Fasano, O., J.B. Crechet, E. De Vendittis, R. Zahn, G. Feger, A. Vitelli, and A. Parmeggiani. 1988. Yeast mutants temperature-sensitive for growth after random mutagenesis of the chromosomal RAS2 gene and deletion of the RAS1 gene. EMBO J. 7: 3375-3383.

Fraenkel, D.G. 1985. On ras gene function in yeast. Proc. Natl. Acad. Sci. 82: 4740-4744.

Fujiyama, A. and F. Tamanoi. 1986. Processing and fatty acylation of ras1 and ras2 proteins in Saccharomyces cerevisiae. Proc. Natl. Acad. Sci. 83: 1266-1270.

Hanks, S.K., A.M. Quinn, and T. Hunter. 1988. The protein kinase family: conserved features and deduced phylogeny of the catalytic domains. Science 241: 42-52.

Ito, H., Y. Fukuda, K. Murata, and A. Kimura. 1983. Transformation of intact yeast cells treated with alkali cations. $I$. Bacteriol. 153: 163-168.

Kataoka, T., D. Broek, and M. Wigler. 1985. DNA sequence and characterization of the $S$. cerevisiae gene encoding adenylate cyclase. Cell 43: 493-505.

Kataoka, T., S. Powers, C. McGill, O. Fasano, J. Strathern, J. Broach, and M. Wigler. 1984. Genetic analysis of yeast ras1 and RAS2 genes. Cell 37: 437-445.
Kunisawa, R., T.N. Davis, M.S. Urdea, and J. Thorner. 1987. Complete nucleotide sequence of the gene encoding the regulatory subunit of the $3^{\prime}, 5^{\prime}$-cyclic AMP-dependent protein kinase from the yeast Saccharomyces cerevisiae. Nucleic Acids Res. 15: 368-369.

Maniatis, T., E.F. Fritsch, and J. Sambrook. 1982. Molecular cloning: A laboratory manual. Cold Spring Harbor Laboratory, Cold Spring Harbor, New York.

Matsumoto, K., I. Uno, K. Kato, and T. Ishikawa. 1985. Isolation and charcterization of a phosphoprotein phosphatasedeficient mutant in yeast. Yeast 1: 25-38.

Matsumoto, K., I. Uno, Y. Oshima, and T. Ishikawa. 1982. Isolation and characterization of yeast mutants deficient in adenylate cyclase and cAMP-dependent protein kinase. Proc. Natl. Acad. Sci. 79: 2355-2359.

Messing, J. 1983. New M13 vectors for cloning. Methods Enzymol. 101: $20-78$

Messing, J., R. Crea, and P.H. Seeburg. 1981. A system for shotgun DNA sequencing. Nucleic Acids Res. 9: 309-321.

Nasmyth, K.A. and S.I. Reed. 1980. Isolation of genes by complementation in yeast: Molecular cloning of a cell-cycle gene. Proc. Natl. Acad. Sci. 77: 2119-2123.

Nikawa, J., P. Sass, and M. Wigler. 1987a. Cloning and characterization of the low-affinity cyclic AMP phosphodiesterase gene of Saccharomyces cerevisiae. Mol. Cell. Biol. 7: 36293636.

Nikawa, J., S. Cameron, T. Toda, K.M. Ferguson, and M. Wigler. 1987b. Rigorous feedback control of cAMP levels in Saccharomyces cerevisiae. Genes Dev. 1: 931-937.

Powers, S., T. Kataoka, O. Fasano, M. Goldfarb, J. Strathern, J. Broach, and M. Wigler. 1984. Genes in S. cerevisiae encoding proteins with domains homologous to the mammalian ras genes. Cell 36: 607-612.

Powers, S., S. Michaelis, D. Broek, S. Santa Anna-A., J. Field, I. Herskowitz, and M. Wigler. 1986. RAM, a gene of yeast required for a functional modification of RAS proteins and mating pheromone a-factor. Cell 47: 413-422.

Pringle, J.R. and L.H. Hartwell. 1981. The Saccharomyces cerevisiae cell cycle. In The molecular biology of the yeast Saccharomyces. Life cycle and inheritance, (ed. J. Strathern, E. Jones, and J. Broach|, pp. 97-142. Cold Spring Harbor Laboratory, Cold Spring Harbor, New York.

Resnick, R.J. and E. Racker. 1988. Phosphorylation of the RAS2 gene product by protein kinase $A$ inhibits the activation of yeast adenylate cyclase. Proc. Natl. Acad. Sci. 85: 24742478.

Robinson, L.C., J.B. Gibbs, M.S. Marshall, I.S. Sigal, and K. Tatchall. 1987. CDC25: A component of the RAS-adenylate cyclase pathway in Saccharomyces cerevisiae. Science 235: $1218-1221$.

Rose, M.D. and G.R. Fink. 1987. KAR1, a gene required for function of both intranuclear and extranuclear microtubules in yeast. Cell 48: 1047-1060.

Sanger, F., S. Nicklen, and A.R. Coulson. 1977. DNA sequencing with chain-terminating inhibitors. Proc. Natl. Acad. Sci. 74: 5463-5467.

Sass, P., J. Field, J. Nikawa, T. Toda, and M. Wigler. 1986. Cloning and characterization of the high-affinity cAMP phosphodiesterase of Saccharomyces cerevisiae. Proc. Natl. Acad. Sci. 83: 9303-9307.

Sherman, F., G.R. Fink, and J.B. Hicks. 1986. Laboratory course manual for methods in yeast genetics, (ed. F. Sherman, G.R. Fink, and J.B. Hicks), Cold Spring Harbor Laboatory, Cold Spring Harbor, New York.

Schultz, J. and M. Carlson. 1987. Molecular analysis of SSN6, a gene functionally related to the SNF1 protein kinase of Sac- 
charomyces cerevisiae. Mol. Cell. Biol. 7: 3637-3645.

Tanaka, K., K. Matsumoto, and A. Toh-e. 1989. IRA1, an inhibitory regulator of the RAS-cyclic AMP pathway in Saccharomyces cerevisiae. Mol. Cell. Biol. 9: 757-768.

Tatchell, K., L.C. Robinson, and M. Breitenbach. 1985. RAS2 of Saccharomyces cerevisiae is required for gluconeogenic growth and proper response to nutrient limitation. Proc. Natl. Acad. Sci. 82: 3785-3789.

Tatchell, K., D.T. Chaleff, D. Defeo-Jones, and E.M. Scolnick. 1984. Requirement of either of a pair of ras-related genes of Saccharomyces cerevisiae for spore viability. Nature 309: 523-527.

Teague, M.A., D.T. Chaleff, and B. Errede. 1986. Nucleotide sequence of the yeast regulatory gene $S T E 7$ predicts a protein homologous to protein kinases. Proc. Natl. Acad. Sci. 83: $7371-7375$.

Toda, T., S. Cameron, P. Sass, and M. Wigler. 1988. SCH9, a gene of Saccharomyces cerevisiae that encodes a protein distinct from, but functionally and structurally related to, cAMP-dependent protein kinase catalytic subunits. Genes Dev. 2: 517-527.

Toda, T., I. Uno, T. Ishikawa, S. Powers, T. Kataoka, D. Broek, S. Cameron, J. Broach, K. Matsumoto, and M. Wigler. 1985. In yeast, RAS proteins are controlling elements of adenylate cyclase. Cell 40: $27-36$.

Toda, T., S. Cameron, P. Sass, M. Zoller, and M. Wigler. 1987 b. Three different genes in $S$. cerevisiae encode the catalytic subunits of the cAMP-dependent protein kinase. Cell 50: $277-287$.

Toda, T., S. Cameron, P. Sass, M. Zoller, and M. Wigler. 1987a. Cloning and characterization of $B C Y 1$, a locus encoding a regulatory subunit of the cAMP dependent protein kinase in Saccharomyces cerevisiae. Mol. Cell. Biol. 7: 1371-1377.

Uno, I., K. Matsumoto, and T. Ishikawa. 1982. Characterization of cyclic AMP-requiring yeast mutants altered in the regulatory subunit of protein kinase. J. Biol. Chem. 257: 1411014115.

-1983a. Characterization of a cyclic nucleotide phosphodiesterase-deficient mutant in yeast. 1. Biol. Chem. 258: $3539-3542$.

- 1983b. Genetic and biochemical evidence that trehalase is a substrate of cAMP-dependent protein kinase in yeast. $J$. Biol. Chem. 258: 10867-10872.

Uno, I., K. Matsumoto, K. Adachi, and T. Ishikawa. 1984a. Regulation of NAD-dependent glutamate dehydrogenase by protein kinases in Saccharomyces cerevisiae. J. Biol. Chem. 259: $1288-1293$.

1984b. Characterization of cyclic AMP-requiring yeast mutants altered in the catalytic subunit of protein kinase. $I$. Biol. Chem. 259: 12508-12513.

Wilson, R.B. and K. Tatchell. 1988. SRA5 encodes the low-Km cyclic AMP phosphodiesterase of Saccharomyces cerevisiae. Mol. Cell. Biol. 8: 505-510.

Wingender-Drissen, R. and J.U. Becker. 1983. Characterization of phosphoprotein phosphatases and phosphorylase phosphatase from yeast. Biochem. et Biophys. Acta 743: 343350.

Winston, F., F. Chumley, and G.R. Fink. 1983. Eviction and transplacement of mutant genes in yeast. Methods Enzymol. 101: 211-218. 


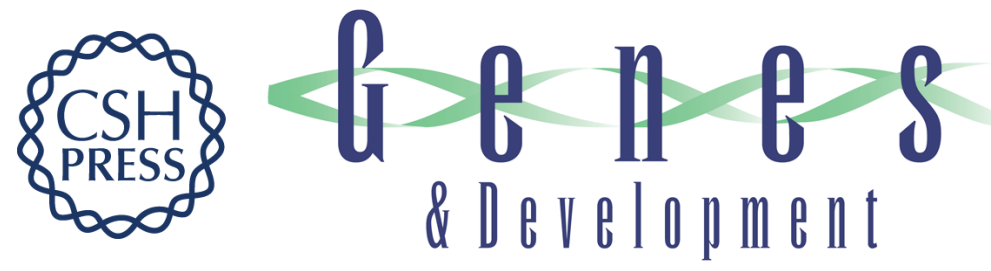

\section{Loss of Ras activity in Saccharomyces cerevisiae is suppressed by disruptions of a new kinase gene, YAKI, whose product may act downstream of the CAMP-dependent protein kinase.}

S Garrett and J Broach

Genes Dev. 1989, 3:

Access the most recent version at doi:10.1101/gad.3.9.1336

References This article cites 54 articles, 30 of which can be accessed free at: http://genesdev.cshlp.org/content/3/9/1336.full.html\#ref-list-1

License

Email Alerting Service

Receive free email alerts when new articles cite this article - sign up in the box at the top right corner of the article or click here.

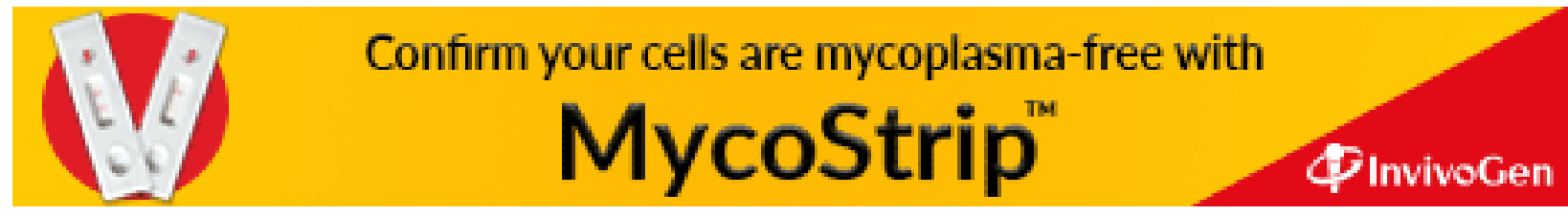

